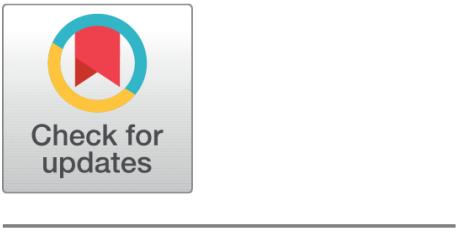

OPEN ACCESS

Received: 19.10.2020

Accepted: 10.12 .2020

Published: 18.12 .2020

Citation: Pareek M, Pandey MK, Priyadarshi P (2020) Emerging technologies enabling the digital transformation of motor insurance in India. Indian Journal of Science and Technology 13(45): 4532-4540. https://doi.org/

10.17485/IJST/v13i45.1846

* Corresponding author.

manoj.pareek@bimtech.ac.in

Funding: None

Competing Interests: None

Copyright: (c) 2020 Pareek et al. This is an open access article distributed under the terms of the Creative Commons Attribution License, which permits unrestricted use, distribution, and reproduction in any medium, provided the original author and source are credited.

Published By Indian Society for Education and Environment (iSee)

ISSN

Print: 0974-6846

Electronic: 0974-5645

\section{Emerging technologies enabling the digital transformation of motor insurance in India}

\author{
Manoj Pareek ${ }^{1 *}$, Manoj Kumar Pandey ${ }^{2}$, Pratik Priyadarshi ${ }^{2}$ \\ 1 Assistant Professor, PGDM -IBM, Birla Institute of Management Technology, Greater Noida, \\ 201306, India \\ 2 Associate Professor, PGDM -IBM, Birla Institute of Management Technology, Greater Noida, \\ 201306, India
}

\section{Abstract}

Objectives: The research study finds out the impact of emerging technologies on the motor insurance market. This study looks at the need for Insurers to align business models with emerging technologies. Methods: This study makes use of secondary data which have examined digital transformation in the motor insurance market in India. We have used the survey findings of the Boston Consulting Group (BCG) and Federation of Indian Chambers of Commerce and Industry (FICCI) covering 3300 internet customers through a representative sample. Findings: The commodification of motor insurance is an opportunity to automate processes for efficiency through the entire customer journey from purchase of insurance to making a claim. Data is very critical to decision-making and using technologies like telematics, machine learning \& artificial intelligence, the insurers can draw better inferences from data to make decisions with an element of speed and efficiency. Novelty: There is paucity of research on motor insurance for Indian market especially to integrate the impact of all technologies in one research study as highlighted here.

Keywords: Motor Insurance; technology; digital; transformation; India

\section{Introduction}

India became the fifth-largest automobile market in the world in 2019 with sales of 3.81 million vehicles. The Indian automobile industry now contributes $7 \%$ to its Gross Domestic Product(GDP). Society of Indian Automobile Manufacturers (SIAM), an association of automobile manufacturers, predicts that by the year 2026, it will contribute $12 \%$ to India's GDP and India would become the third-largest automobile market in the world ${ }^{(1)}$.

This has led to motor insurance taking centre stage as it is the largest contributor of business among all general insurance products. As per the Indian Brand Equity Foundation (IBEF) a government body in FY20, motor insurance had a 36.60 percent market share among all general insurance products in India ${ }^{(2)}$. There is increasing use of Information Technology by insurers for process automation and cost reduction. This involves dealing with a multitude of data and for insurers to succeed they have to be 
driven by data and have to use data to their advantage.

IBEF estimates put cost reduction of total expenditure by 20-30 percent for non-life insurance companies by adopting digitization ${ }^{(3)}$. Motor Insurance as a segment of non-life insurance has been impacted by such endeavours. Activities like recruitment of agents to sell motor insurance, underwriting, issuance of policies, distribution, and claim settlements are areas that have seen beginnings of adoption of digital technologies.

Digital technologies have the potential to transform various operational aspects that affect both insurers and customers of Motor Insurance ${ }^{(4)}$. Motor Insurance comprises two components the first being the compulsory third party (TP)premium fixed in India by the Regulator Insurance Regulatory and Development Authority of India(IRDAI) and the second component being the free to price own damage(OD) premiums. The insurer is free to price its own damage premiums based on its risk assessment practices. There is a cut-throat competition between various insurers for market share in motor insurance putting pressure on margins leading to mounting loss ratios in this segment. The insurers are losing money by doing motor insurance yet the attractiveness of the segment in generating regular cash flow and increasing the top line makes them enter and compete in this line of business.

The growing use of the Internet and consumers using e-commerce websites in India to make purchases has put consumers at an ease of buying motor insurance online. The advent of comparison based websites that offer a choice of customers to buy motor insurance online from many insurers has led to the commodification of insurance. All these factors are aiding the digitalization of the motor insurance market in India.

Motor Insurance is in a stage of transition on the technology front. Several insurers in India have started using emerging technologies with the objectives of improving profitability through cost reduction, pricing risk scientifically, automating claims settlement process with a view to provide a better experience to the end customer. Figure 1 shows various emerging technologies that are impacting the motor insurance market in India.

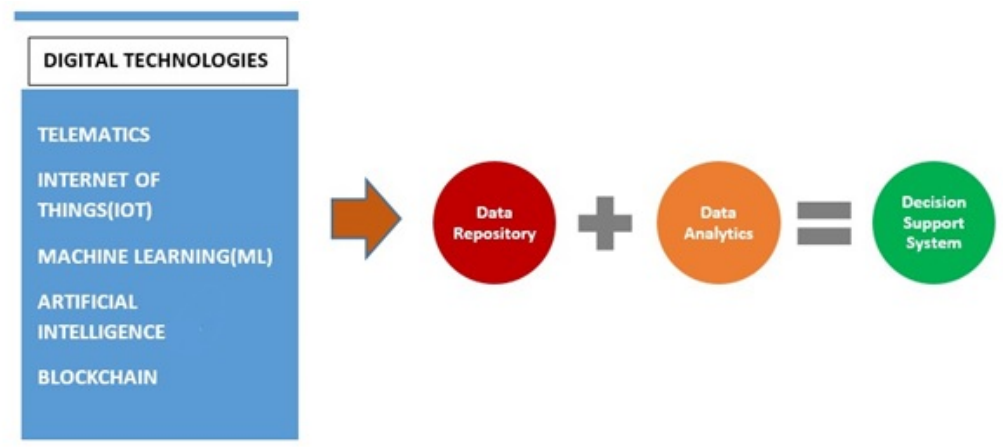

Fig 1. Digital technologies assisting decision support system for insurers

Data Analytics with deep customer insights can help improve existing products and aid in new product development process aligned to customer needs and exact requirements.

This decade has seen the rise of entities called Insure Tech's which make use of emerging technologies and innovative solutions in insurance. InsureTechs should not be seen as disruptors or a threat to existing insurers. The insurers can partner with them to improve upon processes or acquire them ${ }^{(5)}$.

\section{Methods}

We reviewed secondary data published in the last 5 years on emerging technologies and industry adoption of these new technologies in India to examine the impact of emerging technologies on motor insurance and how they can be best used by insurers to their advantage and also whether the customers are ready for engagement through digital platforms for policy administration and claim settlement.

To examine the readiness of Indian consumers to the usage of internet and digital tools we went through the Boston Consulting Group (BCG) and Federation of Indian Chambers of Commerce and Industry (FICCI) survey covering 3300 internet customers through a representative sample drawn from cities having 10-12 lakhs (1 million -1.2 million) plus population and diverse age groups. This survey with a significant sample size gives insights into the mind and behaviour of customers for insurers to make use of various emerging technologies for engaging customer through digital channels, extent of technology adoption and behaviour ${ }^{(6)}$. 


\subsection{Developments in digital arena in insurance sector}

Digital transformation, in brief, is about adapting and using the latest technologies. The implications of a digital transformation involves responding to digital trends outside the control of an organization and transformation is a comprehensive term as it involves management aspects of strategy, leadership, structure to execute the same.

Digital Maturity is a term being increasingly used in management literature and among consultants worldwide. From the customers, perspective it is the ability of individuals to adapt to new digital technologies available to them. In the context of business, it measures the ability to value add by way of using digital technologies to enable the digital transaction. Just as an individual matures with time so does an organization. Digital Maturity is also a differentiator in the market place which determines its overall success. As maturity is a process firms can make improvements to attain maturity digitally to cut down costs and increase customer satisfaction ${ }^{(7)}$.

Digital Transformation involves finding out the technologies in which an insurer can focus its energies on and it does not change the overall goals objectives and strategy of the organization. Digital transformation may bring about personalized product offerings, agility in operations only to serve the consumers which are the reason for the existence of an organization ${ }^{(8)}$.

As a society, more it connected digitally, it moves gradually towards digital maturity which is exhibited by consumer behaviour patterns and responses to digital technologies. Insurers, therefore, need to align business models as per the behaviour of their customers. This is shown in Figure 2 as part of the survey findings of 3300 internet customers done by BCG and FICCI.

\section{RESEARCH AND PURCHASE BEHAVIOUR OF INSURANCE (AMONG INSURANCE BUYERS)}

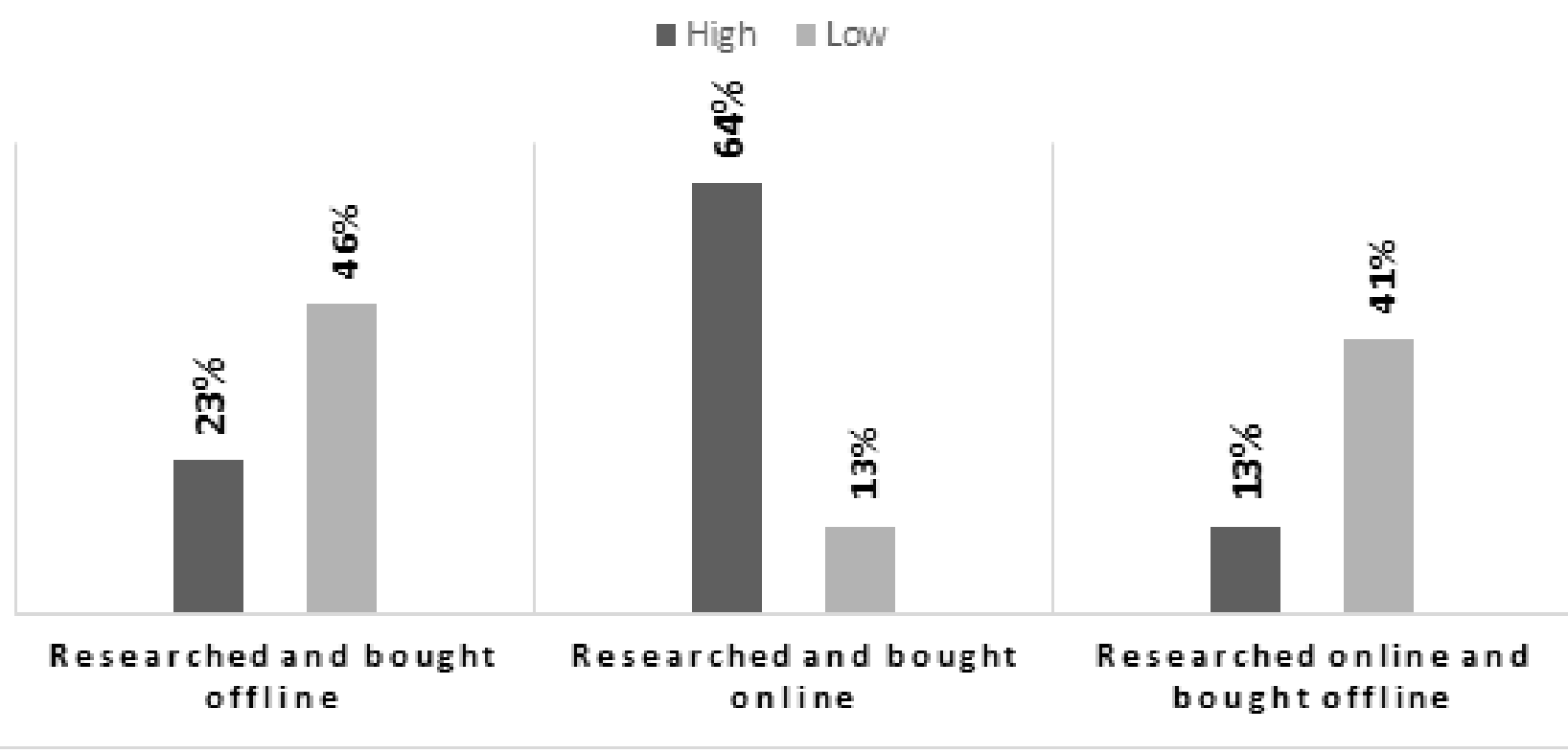

Fig 2. Need to align digital sales model with evolving customer behaviour

Source: BCG-FICCI Survey, 2019. India Insurance India Insurance-Going-from Teens to Twenties

Table 1 shows awareness levels of customers in the BCG survey regarding insurance policies with basic details and terms of the policy.

Table 1. How well do you understand your insurance policy? (Among customers who research online)

\begin{tabular}{lr}
\hline Understand basic details like premium, the sum insured, etc. & $88 \%$ \\
Well comfortable with all the terms & $53 \%$ \\
\hline
\end{tabular}

Source: BCG-FICCI Insurance survey (2019), n=3300

Boston Consulting Group (BCG) India Insurance-Going-from Teens to Twenties 
Figure 3 shows the receptiveness of consumers in the survey to buy insurance from new alternative distribution channels.

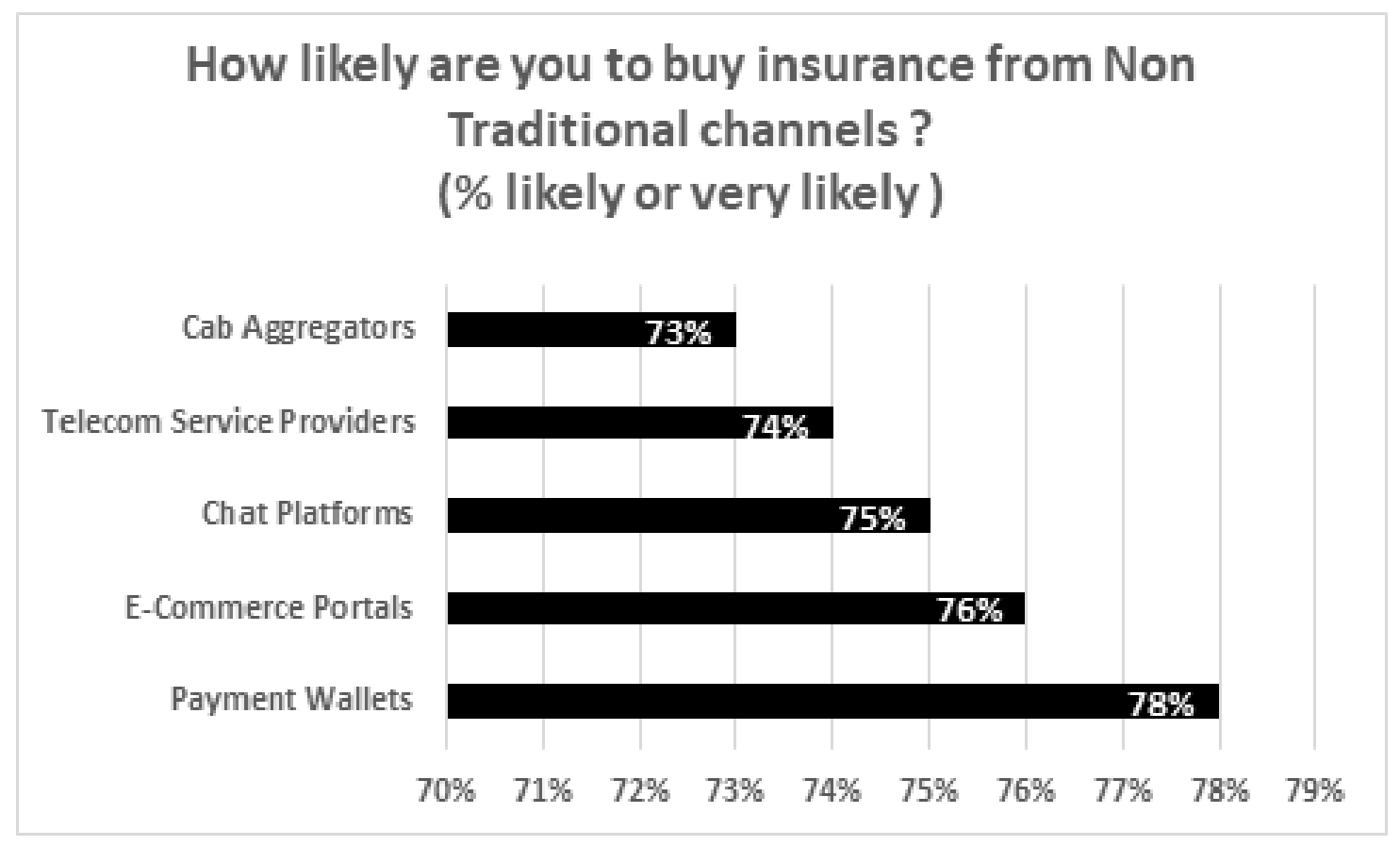

Fig 3. Customer intent to buy from non-traditional channels

Source: BCG-FICCI Insurance survey (2019) n=3300.

Boston Consulting Group (BCG) India Insurance-Going-from Teens to Twenties

Figure 4 presents the type of data the customer in the BCG survey were comfortable sharing within what percentage.

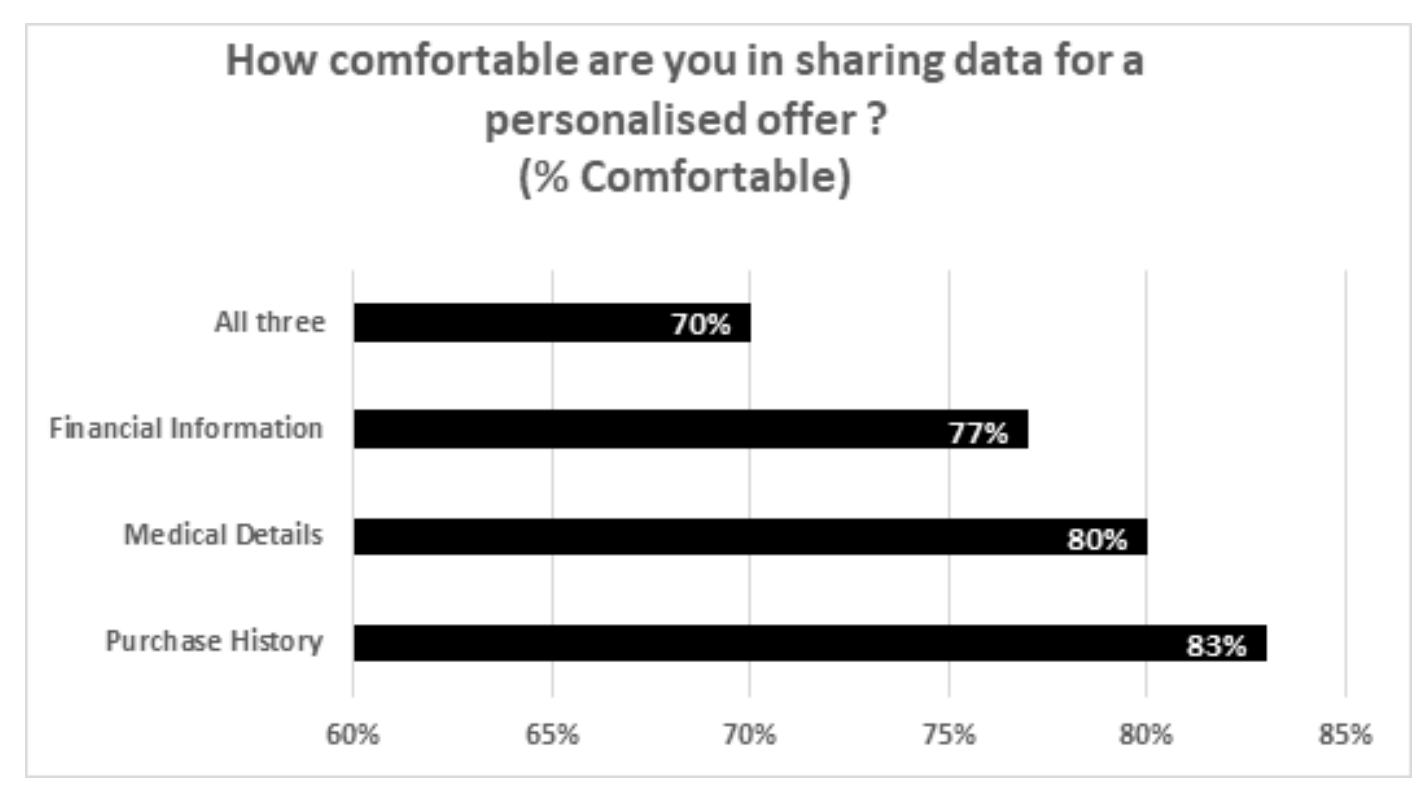

Fig 4. Comfort with sharing data for a personalized product offering

Source: BCG-FICCI Insurance survey (2019) n=3300.

Boston Consulting Group (BCG) India Insurance-Going-from Teens to Twenties 
The findings clearly show that customers are willing to use alternative distribution channels and buy innovative products. They are increasingly using the internet to research products before buying them. They are willing to provide data to receive customized products. Awareness levels about insurance products have increased among Indian consumers. Therefore, insurers can make use of appropriate technologies to engage with them to gather data as well as serve them digitally.

Pricing for motor insurance products traditionally in India takes into account factors like make and model of vehicle, type of fuel used, geographic area, etc. The determination of pricing using such factors involves treating all customers with the same yardstick for risk assessment. The emerging technology of use to insurers is Telematics. Telematics uses Global Positioning System (GPS) technology - to put an on-board monitoring device in a vehicle to monitor the driving habits of the customer, vehicle tracking, and distance travelled by using the vehicle. The data on these aspects can be transmitted to the insurer in realtime. The more the vehicle is driven the more the chances of its being exposed to the risk of an accident. Customers driving the vehicle for lesser duration can now be charged differential or lesser premium through the use of telematics ${ }^{(9)}$. What started as an on-board specialized device in a vehicle has seen a change in form with applications capturing similar data by the installation of an application on a smartphone to monitor driving behaviour and usage.

Telematics leads to better profiling of customers according to the risk involved and is a scientific approach for premium determination. IRDAI the regulator has endorsed the usage of telematics and has come out with policy guidelines to issue named policies which identify the person driving the vehicle for private car and two-wheelers motor polices to assist insurers in risk assessment ${ }^{(10)}$.

Many insurers in India have come out with 'pay as you use' or 'pay how you use' policies as trial products under sandbox regulations of the Insurance Regulatory and Development Authority of India (IRDAI) The sandbox regulations have provided insurers to experiment with and launch innovative products making use of technology and data.

Telematics will help in targeting customers of the desired segment through the use of technology and charging appropriate premiums through a data-driven approach that can deepen customer relationships and increase retention rates. Figure 5 shows how using telematics for the decision-making process for an insurer moves.
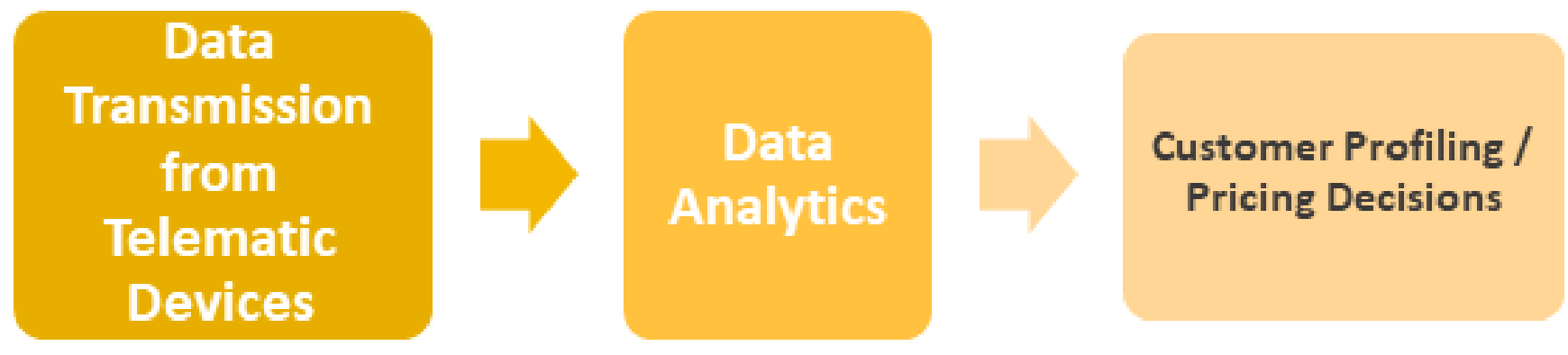

Fig 5. Telematics - Workflow for decision making

Post-accident data can be shared with insurers and analysed on various parameters such as the impact on sensors fitted on brakes, airbags, seat belts, etc. to know the severity of the accident and provide medical assistance if required ${ }^{(11)}$. Table 2 classifies risk indicators for Pay as you drive (PAYD) and Pay how your drive (PHYD)

Table 2. Risk indicators classification

\begin{tabular}{|c|c|}
\hline Exposure-based Insurance (PAYD) & Behaviour-based Insurance (PHYD) \\
\hline $\begin{array}{l}\text { Total distance is driven by the user (the higher the mileage the } \\
\text { higher the risk) }\end{array}$ & $\begin{array}{l}\text { Speeding expressed either as a percentage of kilometres/time driving } \\
\text { over the speed limit or a percentage of speeding }\end{array}$ \\
\hline $\begin{array}{l}\text { Road network type (increased frequency of accidents in the cities, } \\
\text { increased accident severity outside) }\end{array}$ & Harsh acceleration or braking \\
\hline $\begin{array}{l}\text { Risky hours driving (increased accident frequency during a } \\
\text { particular range of hours) }\end{array}$ & $\begin{array}{l}\text { Driver's accident history (severity and the circumstances of the } \\
\text { accident) }\end{array}$ \\
\hline $\begin{array}{l}\text { Trip frequency (a driver is more likely to cause an accident during } \\
\text { an infrequent trip) }\end{array}$ & Seatbelt use \\
\hline Vehicle type & Mobile phone use \\
\hline
\end{tabular}

Source: Dimitrios I. Tselentis et al. / Transportation Research Procedia 14 (2016) 362 - 371 
In India, many insurers have filed products on a pay as you use model under existing Sandbox regulations and the products are under trial phase and time will tell how the products fare in the long run. Table 3 shows general insurers in India who have launched pay as you use motor insurance in India making use of telematics.

Table 3. Pay as you use products introduced by general insurers in India

\begin{tabular}{lll}
\hline General Insurer & Product Format & Type of Product \\
\hline Bharti Axa & Customer pre declares usage for a year. Slabs of 2500 /5000/7500 Km & Under Sandbox regulations \\
Tata AIG & Customer can choose $2500 \mathrm{Kms}$ to $25000 \mathrm{Kms}$ with a facility of top-up & Under Sandbox regulations \\
ICICI Lombard & Pay as you use model with a discount of 5 -10\% on OD premium on km driven & Under Sandbox regulations \\
Edelweiss & $\begin{array}{l}\text { Pay-as-you-use model. Customer pays the premium only on the days they use the } \\
\text { vehicle, offering significant cost savings and convenience. Customers can use the }\end{array}$ & Under Sandbox regulations \\
& $\begin{array}{l}\text { app to SWITCH their policy cover 'ON' and 'OFF', depending on whether they are } \\
\text { driving that day }\end{array}$ & \\
\hline
\end{tabular}

Insurers have the advantage of having the personal data of customers from auto insurance policies. Insurers require prowess in areas of analytical tools, mobile sensing technology, and customer interfaces. Several OEMs are thinking of coming out with vehicles with inbuilt telematics devices from the factory assembly line and advent of ride-sharing providers such as Uber and Ola are gaining traction with stronger network management. Insurers need to work towards moving from risk aggregation to risk prevention ${ }^{(12)}$.

\subsection{Application of internet of things (IOT)}

Estimates of International Data Corporation (IDC) predict expenditure growth on IoT (Internet of Things) at a Compounded Annual Growth Rate (CAGR) of 14.4 percent from 2017-2021. IoT through the use of sensors and devices gives real-time data to insurers which helps them support decision-making in powerful ways ${ }^{(13)}$.

The marriage of IoT and telematics assists insurers to find out things like the location and speed of insured vehicles using real-time data. This can be further analysed for risk assessment of customers by putting them in categories based on driving behaviour and usage to design and price products ${ }^{(14)}$.

Insurers in India who make use of IoT can have better product design capabilities than competitors. This will lead to customization of products and remove the age-old practices of risk assessment based on observational data which creates one size fits all approach to product development ${ }^{(15)}$.

Automobile insurance has to be seen as part of an ecosystem where relationships with other stakeholders matter like alliances with OEM's (Original Equipment Manufacturers) which make it possible to integrate risk in existing products. Similarly, insurers can partner with the Internet of Things (IoT) providers to further customer engagement during the entire customer journey through various touchpoints ${ }^{(16)}$.

\subsection{Applications of artificial intelligence (AI)}

AI enables machines to perform thinking abilities akin to humans. In real life, AI has found application in real- autonomous cars $^{(12)}$. AI has the potential and power to disrupt the insurance industry. One of the facets of AI is Machine learning(ML) which is the potential of machines to use statistical techniques and algorithms to predict results with accuracy and speed ${ }^{(17)}$.

Machine learning algorithms can help in designing a product, planning sales, providing services, and settling claims. It can help in fraud detection, evaluating risk, and identification of opportunities to cross-sell products. All these are being used at the back end by insurers in vehicle insurance space ${ }^{(18)}$.

Mobile applications assist insurers in customer engagement and routine servicing requirements on a 24/7 basis. Chatbots which make use of AI (Artificial Intelligence) can have intelligent conversations with customers and can address frequently asked queries in a better way than traditional Chatbots. Natural Language Processing (NLP) allows customers to speak to robotic agents who recognize voice besides having a text chat to service customers ${ }^{(18)}$. Several insurers have provided the facility of mobile applications for customers to initiate claims by taking photographs themselves and submit the same for assessment. Claims till a particular limit are settled on a self-assessment basis making use of algorithms to estimate damages and settle claims by paying customers directly in a short period. This improves customer experience and automating claim settlement processes for insurers ${ }^{(19)}$.

Artificial Intelligence (AI) is using to document recognition systems to make sense of hand-filled claims forms instantly to capture data to reduce human intervention thereby increasing speed in processing of claims. Audio analysis or voice recognition 
at the time of making claims by a customer can help analyse voice patterns to detect and prevent fraud. Robotic Process Automation (RPA) can help support customer service requests through the use of Chatbots for routine requests like change in contact details, address updating, etc. ${ }^{(20)}$.

\subsection{Application of blockchain}

Blockchain offers a solution for insurers to move away from the manual process of managing data. Blockchain enables insurers to record and validate transactions, which are verifiable and that is updated in real-time involving the use of cryptography and a distributed messaging protocol to create a dispersed, or common, ledger among transaction counterparties ${ }^{(21-23)}$.

The insurance sector having a legacy of manual systems and processes for a long time this provides an opportunity for the adoption of digital technology to bring efficiency in processes like paying claims, handling customer renewals, and improving service Turnaround Times(TAT) for its customers ${ }^{(24)}$.

Vehicle Insurance policies in India provide for what is called No Claim Bonus (NCB) which is a discount is given to customers in case of no claim made in a policy year in the subsequent year. This is difficult to verify since customers are free to change insurers each year. Self-declaration by a customer of having made no claim is the only way of verification. ICICI Lombard General Insurance India 's largest private non-life insurer has successfully tested blockchain technology to verify the existence of NCB for a vehicle at the time of Insurance. This is going to be adopted by other insurers leading to the reduction of fraud and increased efficiencies.

Manual processes arise due to a lack of trust between parties leading to depending upon intermediaries like brokers to create trust. The regulatory framework further supports this framework ${ }^{(25)}$. Figure 6 shows how data flows in the vehicle insurance value chain.

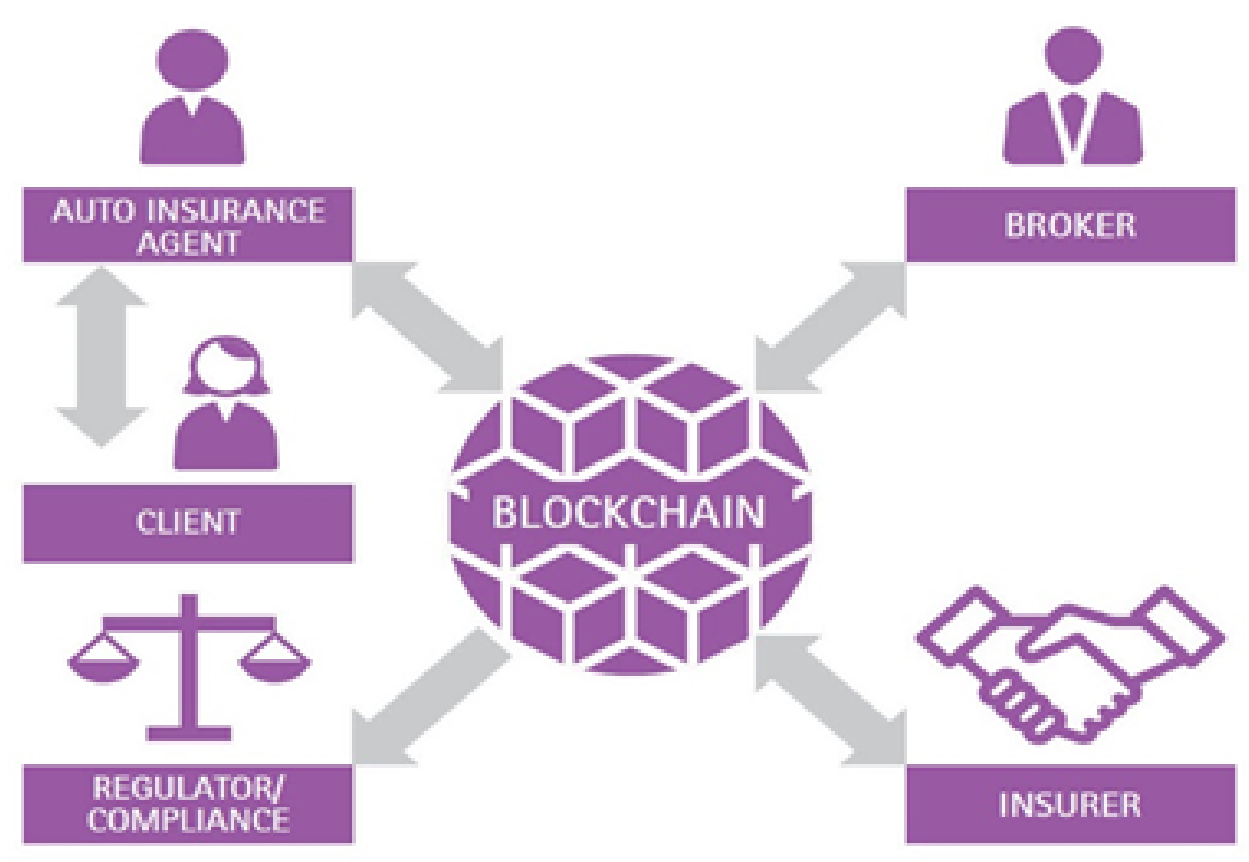

Fig 6. Single source data across the broker-insurer value chain

Source: Accenture Insurance Blog (2020): Blockchain-A-New-Building-Block-For-Transparency

Predictive analytics can help to analyse can help in the formulation of marketing strategies that are customer-centric to profile customer customers on various parameters to introduce new products catering to specific segments and reduce or increase 
prices. With technologies like telematics, machine learning \& artificial intelligence insurers can draw better inferences from data to make underwriting decisions with an element of speed and efficiency ${ }^{(26,27)}$.

\section{Conclusion}

Insurers receive data from customers and it is up to them how to use data to their advantage. As it has been said that Data is the new oil now. As finding oil and extracting it, is a tedious process so is data processing and analytics. Data is very critical to decision making and technology just enables insurers to do that. As India becomes a more digitally oriented and connected society more and more data is available to insurers now to take decisions. Though there are questions of data privacy, ensuring its safety is a concern area for insurers. Customer' consent is necessary for sharing data and regulatory concerns regarding data privacy need to be seen before any insurer embarks on using emerging technologies.

Claims cost reduction determines the profitability of insurers. It has a strong interlinkage with underwriting practices. Automating underwriting and cutting costs would help them guarantee profitability as well as customer satisfaction. Intelligent use of data by insurers would a key differentiator to succeed in a digital age. Data-driven decision support systems make customers feel more connected with insurers getting insights about their behaviour, price, and improve overall customer engagement.

Insurers who cannot use data intelligently through various emerging technologies would be the laggards in an extremely competitive marketplace. For customers to have the confidence to share data with insurers. The insurers should develop a perception whereby customers develop a feeling of trust to exchange data with them.

Technology-led transformation is about innovation and firms using a customer-centric approach will succeed in the marketplace. InsureTechs would come with more innovative solutions. Insurers will require creativity in product design as technology is only an enabler not a solution by itself. The differentiation in the market place would be innovative new products that are customized to customer needs. Legacy systems would need to transform into new business models that support the digital ecosystem.

Insurers need to create innovation hubs within firms. Firms need to strike partnerships with InsureTech companies in case the current structures do not support a digital transformation internally. Otherwise, it can be a combination of both in house and third party expertise to succeed in a digital age.

The sandbox regulations put forth by the regulator IRDAI provides insurers a platform for innovation in product development and solutions. New product development requires a multidisciplinary approach where functions like marketing, underwriting, claims, and operations integrate efforts to offer innovative solutions. Insurers have to shift gears within the organization to break away from the traditional way of product development to using technology for product design and delivery. Motor Insurance fortunes are tied up closely with that of the automotive industry. Shared mobility companies made good use of data analytics to drive efficiencies. A rethink of the current model is required by insurers to gain insights into consumer behaviour right from whom the customer buys and how motor insurance is bought to anticipate changing digital transformation impact in the auto insurance market by insurers. Motor insurance purchase in India is getting digitized with the advent of alternative channels like the point of salespersons (POS), web aggregators, and online brokers.

Each insurer has to decide whether the digital transformation using technologies is consistent with the overall strategy and goals of an organization. Digital transformation using emerging technologies requires a mind-set change within human resources within the organization. This can be approached gradually on a modular basis across functional areas rather than a sudden major overhaul where the existing human resources are not prepared to deliver to customers in a changing environment.

The commodification of motor insurance is an opportunity to automate processes for efficiency through the entire customer journey from making a purchase to making a claim. Digital Transformation requires a strategy, research orientation, and finally marketing prowess to communicate benefits to customers. Technology is an enabler, not an end as insurers who come first with innovative products that customers want to buy will be successful in the long term.

\section{Acknowledgments}

We would not have been able to write the research article without the support of Chairperson-Insurance Business Management programme Prof. (Dr.) Abhijit Chattoraj and colleagues at Birla Institute of Management Technology who extended their support and help.

\section{References}

1) Annual Report 2018-19. 2018. Date accessed: 13/09/2020. Available from: http://www.siam.in/uploads/ar/21-21stAnnualReport2018-2019.pdf. 
2) Indian Automobile Industry Analysis. . Available from: https://www.ibef.org/archives/industry/automobiles-reports/indian-automobiles-industryanalysis-march-2020.

3) Insurance sector in India: Industry overview, market size \& trends. . Available from: https://www.ibef.org/industry/insurance-sector-india.aspx.

4) Digital Transformation Roadmap. . Available from: http://www.siam.in/uploads/filemanager/148DigitalTransformationRoadmapATKearneyLaunchDeckvF. pdf.

5) Liu E. 4 Challenges in Moving to Digital Insurance Digital Strategy Liferay Blogs. . DateAccessed:09/10/2020. Available from: https://www.liferay.com/ blog/en-us/digital-strategy/4-challenges-in-moving-to-digital-insurance.

6) Going from Teens to Twenties. . Available from: http://media-publications.bcg.com/India-Insurance-Going-from-Teens-to-Twenties.pdf.Dateaccessed.

7) Kane GC. Digital Maturity, Not Digital Transformation. . Available from: https://sloanreview.mit.edu/article/digital-maturity-not-digital-transformation.

8) Shipilov A, Nathan F. Digital doesn't have to be disruptive Harvard Business Review. . Available from: https://hbr.org/2019/07/digital-doesnt-have-tobe-disruptive.

9) Telematics and tracking devices change car insurance in the future. . Available from: https://www.icicilombard.com/insurance-information/travelinsurance-info/article/the-future-of-car-insurance-tracking-devices-and-telematics.

10) Jenkins C. Telematics \& Motor Insurance in India. . Dateaccessed:13/09/2020. Available from: https://www.mondaq.com/india/insurance-laws-andproducts/717366/telematics-motor-insurance-in-india.

11) Tselentis DI, Yannis G, Vlahogianni EI. Innovative Insurance Schemes: Pay as/how You Drive. Transportation Research Procedia. $2016 ; 14: 362-371$. Available from: https://dx.doi.org/10.1016/j.trpro.2016.05.088.

12) Markus L. Shifting gears: Insurers adjust for connected-car ecosystems. . Available from: https://www.mckinsey.it/idee/shifting-gears-insurers-adjustfor-connected-car-ecosystems.

13) The Internet of Things in insurance. . Available from: https://www.eycom.ch/en/Publications/20161109-The-Internet-Of-Things-in-insurance/ download.

14) Dua V. The potential of IoT in the Indian insurance industry. . Available from: https://trak.in/tags/business/2017/11/18/potential-of-iot-in-indianinsurance-industry/.

15) Faheem S. How salesforce is enabling organizations to tide over COVID-19. . Available from: https://www.damcogroup.com/blogs/Insurance-DataAnalytics/.

16) Tanguy C, et al. Insurance beyond digital: The rise of ecosystems and platforms. . Available from: https://www.mckinsey.com/industries/financial-services/ our-insights/insurance-beyond-digital-the-rise- of-ecosystems-and-platforms.

17) Microsoft News Center India. Artificial Intelligence to more than double the rate of innovation in India by 2021. . Available from: https://news.microsoft. com/en-in/artificial-intelligence-rate-of-innovation-microsoft-idc-study/.

18) Rajamani S. Driving opportunities for insurers through Artificial Intelligence. . Available from: https://www.mindtree.com/blog/driving-opportunitiesinsurers-through-artificial-intelligence.

19) Trends for 2019 - KPMG global. . Available from: https://home.kpmg/xx/en/home/insights/2019/02/insurtech-10-trends-for-2019-fs.html.

20) Insuretech. The game changer for the insurance sector in the next normal. . Available from: https://www.dqindia.com/insuretech-game-changerinsurance-sector-next-normal/.Date.

21) Blockchain in the Indian insurance market - insights from Policy bazaar. . Available from: https://insureblocks.com/ep-36-blockchain-in-the-indianinsurance-market-insights-from-policybazaar/.

22) Jenkins C. Blockchain technology in the Indian insurance sector. . Available from: https://www.mondaq.com/india/insurance-laws-and-products/ 729182/blockchain-technology-in-the-indian-insurance-sector.

23) Singla S, Suprita A, Shubham S, Sandeep S, Amit R. How blockchain could be A game changer in India. . Available from: https://inc42.com/resources/ how-blockchain-could-be-a-game-changer-in-india/.

24) Blockchain and DLT. . Available from: https://www.hoganlovells.com/en/service/blockchain.

25) Blockchain: a new building block for transparency - Accenture Insurance Blog. . Available from: https://insuranceblog.accenture.com/blockchain-a-newbuilding-block-for-transparency.

26) Pricewaterhousecoopers. Insurance 2020: The digital prize - taking customer connection to a new level. . Available from: https://www.pwc.com/gx/en/ industries/financial-services/publications/digital-non-life.html.

27) Priya S. . Available from: https://auto.economictimes.indiatimes.com/news/industry/motor-insurance-set-to-rally-on-new-models-festive-seasonicici-lombard/77777052. 